\title{
Research on the Influence of Development Scenarios on the OLCOE of Wind Power: A Case Study of China
}

\author{
Chao Liang, ${ }^{1,2}$ Jing Zhang $\mathbb{D}^{1},{ }^{1}$ Yongqian Liu $\mathbb{D}^{1},{ }^{1}$ Jie Yan, ${ }^{1}$ and Wei $\mathrm{He}^{3}$ \\ ${ }^{1}$ State Key Laboratory of Alternate Electrical Power System with Renewable Energy Sources (NCEPU), \\ School of Renewable Energy, North China Electric Power University, Changping, Beijing 102206, China \\ ${ }^{2}$ Guodian Technology \& Environment Group Corporation Limited, Beijing 100039, China \\ ${ }^{3}$ State Grid Jiangxi Electric Power Research Institute, Nanjing, Jiangsu 330096, China \\ Correspondence should be addressed to Yongqian Liu; yqliu@ncepu.edu.cn
}

Received 22 April 2020; Revised 24 August 2020; Accepted 8 December 2020; Published 24 December 2020

Academic Editor: Qian Zhang

Copyright (C) 2020 Chao Liang et al. This is an open access article distributed under the Creative Commons Attribution License, which permits unrestricted use, distribution, and reproduction in any medium, provided the original work is properly cited.

\begin{abstract}
To achieve a high penetration of renewable energy, wind power development in China has gradually moved to diverse manifestation (e.g., centralized onshore, low wind speed, and offshore wind power). However, preexisting studies regarding wind power cost neglect to consider the respective characteristics of different development scenarios. In this paper, the overall levelized cost of energy (OLCOE) model is established for different scenarios. Taking China's wind farm data as an example, the impact of development scenarios and wind power permeability on OLCOE and its cost components is quantitatively analysed. The results show that, (1) in the low penetration scenario, low wind speed power has the best economy and is beneficial to the conventional units; (2) the large-scale development of offshore wind power requires a reduction in the cost of offshore wind turbines and submarine cables; and (3) at present, onshore centralized wind power has economic advantages, but there is little room for its cost reduction.
\end{abstract}

\section{Introduction}

Rapid global energy transformation is bringing, within reach, an era with a high share of renewables. According to research by the International Energy Agency (IEA), the share of renewable electricity in global primary energy consumption will rise to $23.8 \%$ by 2030 . In China, as of the end of 2018, the installed renewable capacity accounted for $38.3 \%$ of the total, up by $1.7 \%$ the previous year. Therefore, China is playing a very important role in the transformation process. As of the end of 2018, China had an installed renewable capacity of 728 million $\mathrm{kW}$ and an installed wind capacity of 184 million $\mathrm{kW}$, up by $12 \%$ and $12.4 \%$, respectively, over the previous year. Among various forms of clean energy, wind power is developing the fastest and is the most established commercial industry. However, the levelized cost of energy (LCOE) for wind power is still considerably higher than that for conventional forms of energy such as thermal power and hydropower $[1,2]$. The need to reduce the costs of wind power is increasingly clear.
Significant progress has been made by researchers, with a focus on the costs of wind power. However, these studies only focus on one aspect of cost (e.g., only generation cost, or transmission cost, or integration cost) and do not give the overall cost of wind power in the process of generation, transmission, and integration.

The generation cost of wind power refers to the annual investment of a wind farm divided by the annual energy production. A modelling method for wind power production and its unpredictability is proposed by analysing the technical limitations of a series of wind turbines, and then the generation cost of wind power and its effect on carbon dioxide emission are discussed [3]. The LCOE for future wind power is estimated with the learning curve method, and the results show that the LCOE for onshore wind power will decrease by $13.91 \%$ from 0.40 yuan/kWh in 2016 to 0.34 yuan/kWh in 2025 [4]. An LCOE estimation method taking audit information into account is proposed [5]. The uncertainty of input variables in an LCOE calculation is 
discussed, such as variables related to operation cost, initial investment, and power generation, and then the probabilities and their confidence interval of an LCOE larger than its set threshold are estimated by using the joint probability distribution of the LCOE obtained from the Monte Carlo simulation [6]. The research results on the generation cost of some European wind power projects are summarized, and the results show that the utilization hours and initial investment cost have the greatest effect on the generation cost of offshore wind power. In addition, rising raw-material prices have pushed up the generation cost by more than $20 \%$ in 3 years [7].

The transmission cost refers to the summation of the infrastructure construction costs caused by high-voltage power transmission lines. A new method for estimating the cost of long-distance electricity transmission (LDET) is proposed, which considers markup by power exporters and importers, and then the factors influencing LDET operation cost are assessed with a weighted least squares regression model [8].

The integration cost of wind power refers to the cost per unit of wind power electricity to be safely and stably consumed in the grid. It does not include transmission costs. The whole life cycle cost of wind power incorporating intermittency cost and the backup cost is analysed, and the competitiveness of wind power in four scenarios-natural gas, thermal power, wind power, and wind power coupled with an energy storage system-is assessed. The results show that the lower intermittency cost of wind power can drive down its cost to a level lower than that of thermal power [9]. The results in [10] show that the intermittency cost of wind power still exists when wind power penetration is low. The integration cost is quantified based on the marginal economic value of power and is decomposed according to the temporal variability and uncertainty of wind power. The results show that the reduction of the utilization rate of thermal power leads to a considerable integration cost [11]. Wind power forecasting creates uncertain factors in the power system due to the intermittency of wind generation [12] and brings about additional operation costs caused by forecasting uncertainty. In the context of this, new concepts and a general methodology are proposed to quantify wind power uncertainty incremental cost and wind power uncertainty dispatch cost based on probabilistic forecasting of wind power [13].

On this basis, the concept of overall levelized cost of energy (OLCOE) for wind power is introduced in the authors' previous work, covering generation cost, transmission cost, and integration cost. The integration cost model quantifies the cost of grid auxiliary services and the cost caused by changes in the operating characteristics of conventional units [14].

In addition to the lack of comprehensiveness of the wind power cost model, the differences between development scenarios are also worthy of attention. Most large windpower bases in China are generally located in the northeast, northwest, and north of China, far away from load centers in the east. For these regions, the system LCOE for wind power is high due to the cost of transmission and power curtailment. To improve integration, wind power sources in China are being diversified with offshore, low wind speed, and centralized onshore wind power. A rather balanced mix, instead of the dominance assumed by large-scale centralized onshore wind power, is forming.

Different development scenarios of wind power have their own characteristics and advantages in the process of generation, transmission, and integration. These characteristics lead to differences in the composition of system LCOE. Realizing a higher proportion of wind power integration requires a comprehensive understanding of the system LCOE in different scenarios. It can help guide researchers and policymakers on optimizing development strategies.

Many researchers work extensively on wind power cost under specific scenarios. A life cycle cost model (LCC) for offshore wind power by considering factors, such as location, water depth, and distance to shore, is developed to compare the economics of three different offshore wind farms [15]. The results in $[16,17]$ show that the location and type of supporting structure of offshore wind farms have a large effect on the overall cost of offshore wind power. A cost model for offshore wind power in the operating period is developed, and the sensitivity of the cost is assessed [18]. The LCC of offshore wind power with high-voltage alternating current (HVAC) and high-voltage direct current (HVDC) technologies is compared, respectively [19]. The LCOE of floating offshore wind power is analysed, and the results show that the LCOE is greatly affected by water depth and distance to shore [20]. The calculation method for balance cost and variability cost of onshore wind power is proposed [21-23]. The relationship between levelized cost and blade diameter of wind turbines at low wind speed is examined [24].

However, the above studies only focus on a single wind power scenario. They neither address structural differences in the system LCOE under the scenarios of onshore, offshore, and low wind speed, nor perform a comparison of the costs at different penetration levels. For the above areas still to be addressed, this work constructs OLCOE models for each of the scenarios based on characteristics of their cost components. To test the validity of the models, scenariospecific parameters are input into the models for comparing each of the cost components under different scenarios; and the relationship between the OLCOE for wind power and the penetration level is also quantified.

The study is structured as follows. Section 2 presents the modelling method for the OLCOE of wind power. Section 3 analyses the differences between different development scenarios for wind power. Section 4 compares the OLCOE for wind power and its components under different scenarios, including different penetration levels and different wind power development modes. A sensitive analysis is also conducted to identify how dependent the OLCOE is on the involved variables. Section 5 summarizes this work. Abbreviations and variables in this paper are shown in Table 1. 
TABLE 1: Abbreviation.

\begin{tabular}{|c|c|c|}
\hline Name & Meaning & Unit \\
\hline $\mathrm{AOE}_{1}$ & Annual operating expenses of wind power & \$/year \\
\hline $\mathrm{AOE}_{2}$ & Annual operating expenses of thermal power & \$/year \\
\hline AEP & Annual energy production & $\mathrm{kW} \cdot \mathrm{h} /$ year \\
\hline$b$ & Standard coal consumption for power supply & $\mathrm{g} / \mathrm{kW} \cdot \mathrm{h}$ \\
\hline$C_{\text {wind }}$ & Generation cost of wind power & $\$ / \mathrm{kW} \cdot \mathrm{h}$ \\
\hline$C_{\text {trans }}$ & Transmission cost & $\$ / \mathrm{kW} \cdot \mathrm{h}$ \\
\hline$C_{\text {int }}$ & Integration cost & $\$ / \mathrm{kW} \cdot \mathrm{h}$ \\
\hline$C_{\text {unit1 }}$ & Initial capital cost of wind power & $\$ / \mathrm{kW}$ \\
\hline$C_{\text {unit2 }}$ & Initial capital cost of thermal power & $\$ / \mathrm{kW}$ \\
\hline$C_{\text {thermal }}$ & Generation cost of thermal power & $\$ / \mathrm{kW} \cdot \mathrm{h}$ \\
\hline$C_{\text {infra }}$ & Annual total investment in power transmission and transformation & $\$$ \\
\hline$C_{\text {loss }}$ & Electricity loss cost of transmission lines & \$/year \\
\hline$C_{O \& M}$ & Annual operation and maintenance cost of lines & $\$ /$ year \\
\hline$C_{\text {com }}$ & Compensator investment of unit capacity & $\$ /$ Mvar \\
\hline$C_{\text {service }}$ & Ancillary cost & $\$ / \mathrm{kWh}$ \\
\hline$C_{\text {profile }}$ & Profile cost & $\$ / \mathrm{kWh}$ \\
\hline$C_{\text {balance }}^{\text {promie }}$ & Balance cost & $\$ / \mathrm{kW} \cdot \mathrm{h}$ \\
\hline$C_{\text {backup }}$ & Backup cost & $\$ / \mathrm{kW} \cdot \mathrm{h}$ \\
\hline $\mathrm{CRF}_{1}$ & Fixed charge rate of wind power & None \\
\hline $\mathrm{CRF}_{2}$ & Fixed charge rate of thermal power & None \\
\hline $\mathrm{CRF}_{3}$ & Fixed charge rate of transmission and transformation & None \\
\hline$I$ & Total investment in transmission and transformation & $\$$ \\
\hline$I_{1}$ & Total investment of converter station & $\$$ \\
\hline$I_{2}$ & Total investment of transmission lines & $\$$ \\
\hline$I_{3}$ & Total investment of reactive power compensation devices & $\$$ \\
\hline$I_{\text {unit1 }}$ & Converter/substation investment of unit capacity & \$/MVA \\
\hline$I_{\text {unit2 }}$ & $\mathrm{DC} / \mathrm{AC}$ line investment per unit length & $\$ / \mathrm{km}$ \\
\hline$k$ & Penetration level of wind power & None \\
\hline$L_{e}$ & Transmission distance & $\mathrm{km}$ \\
\hline LLC & Land lease cost & $\$ /$ year \\
\hline LRC & Levelized replacement/overhaul cost & \$/year \\
\hline OLCOE & Overall levelized cost of energy & $\$ / \mathrm{kW} \cdot \mathrm{h}$ \\
\hline$O \& M$ & Annual operation and maintenance cost of wind power & \$/year \\
\hline$p_{c}$ & Coal price & $\$ / \mathrm{kg}$ \\
\hline$P_{\max }$ & Maximum power of DC/AC lines & MW \\
\hline$P_{\text {com }}$ & Compensator capacity & Mvar \\
\hline$Q^{\operatorname{com}}$ & Calorific value of standard coal & $\mathrm{kcal} / \mathrm{kg}$ \\
\hline$q$ & Calorific value of coal & $\mathrm{kcal} / \mathrm{kg}$ \\
\hline$r_{\text {loss_t } t}$ & Power loss rate of converter/substation station & None \\
\hline$r_{\text {loss } \_l} l$ & Power loss rate of $\mathrm{DC} / \mathrm{AC}$ lines & None \\
\hline$R$ & Resistance per unit length & $\Omega / \mathrm{km}$ \\
\hline$r_{\text {oper }}$ & Annual operating maintenance rate of lines & None \\
\hline$T_{\text {wind }}$ & Utilization hours of wind power & $\mathrm{h}$ \\
\hline$T_{\text {thermal }}$ & Utilization hours of thermal power & $\mathrm{h}$ \\
\hline$U_{n}$ & Rated voltage of lines & $\mathrm{kV}$ \\
\hline$W^{n}$ & Annual electricity received by load & $\mathrm{kW} \cdot \mathrm{h} /$ year \\
\hline$W_{\text {loss }}$ & Annual electricity loss & $\mathrm{MW} \cdot \mathrm{h} /$ year \\
\hline$W_{\text {loss } \_t}^{\text {loss }}$ & Annual electricity loss of converter/substation stations & $\mathrm{MWh} /$ year \\
\hline$W_{\text {loss_l } l}$ & Annual electricity loss of lines & MWh/year \\
\hline$W_{\text {wind }}^{\text {loss } t}$ & Electricity generated by wind power & $\mathrm{kW} \cdot \mathrm{h}$ \\
\hline$W_{\text {thermal }}$ & Electricity generated by thermal power & $\mathrm{kW} \cdot \mathrm{h}$ \\
\hline$\tau$ & Maximum load loss hours & h \\
\hline$\alpha$ & Capacity credit of power system & None \\
\hline$\alpha_{\text {wind }}$ & Capacity credit of wind power & None \\
\hline
\end{tabular}

\section{OLCOE Model for Wind Power}

In this study, OLCOE for wind power is defined as total expenses incurred in the processes of producing, transporting, and integrating unit wind power [14], as shown in the following equation:

$$
\text { OLCOE }=C_{\text {wind }}+C_{\text {trans }}+C_{\text {int }} \text {, }
$$

where $C_{\text {wind }}$ is the levelized generation cost $(\$ / \mathrm{kWh}) ; C_{\text {trans }}$ is the levelized transmission cost $(\$ / \mathrm{kWh})$; and $C_{\text {int }}$ is the levelized integration cost $(\$ / \mathrm{kWh})$. 
Traditional LCOE for wind power only involves the generation cost. However, in reality, the overall cost of the power system in the integration process rises remarkably due to antipeak-shaving property for wind power and its unique variability and uncertainty. Therefore, this study introduces the concept of OLCOE to reflect the actual cost of wind power.

2.1. Generation Cost of Unit Electricity. The generation cost of unit electricity for wind power is calculated as shown in equation (2). Offshore wind power includes the following additional capital costs: marinization, offshore support structure, offshore transportation, port and staging equipment, personnel access equipment, scour protection, surety bond, and offshore warranty premium. Different types of wind turbines have different computing formulas for the cost of gearbox, generator, and mainframe. The inputs include the following: rated power, rotor diameter, hub height, cut-in, cut-out, and rated wind speed. The details in the computing method can be found in [25]:

$$
C_{\text {wind }}=\frac{C_{\text {unit } 1} \times \mathrm{CRF}_{1}}{T_{\text {wind }}}+\mathrm{AOE}_{1},
$$

where $C_{\text {unitl }}$ is the initial capital cost of the wind turbine $(\$ / \mathrm{kW}) ; \mathrm{CRF}_{1}$ is the fixed charge rate of wind power; $\mathrm{AOE}_{1}$ is the annual operating expenses of wind power; and $T_{\text {wind }}$ is the utilization hours of wind power.

As the installed thermal capacity in China is relatively high, thermal power units are assumed as representative units for peak frequency modulation. The generation cost of unit electricity for thermal power units is calculated as shown in the following equation [26]:

$$
C_{\text {thermal }}=\frac{C_{\text {unit2 }} \times \mathrm{CRF}_{2}}{T_{\text {thermal }}}+\frac{\mathrm{Q} \times b \times p_{c}}{q}+\mathrm{AOE}_{2} \text {, }
$$

where $C_{\text {unit2 }}$ is the initial capital cost of the thermal power unit $(\$ / \mathrm{kW}) ; \mathrm{CRF}_{2}$ is the fixed charge rate of thermal power; $T_{\text {thermal }}$ is the utilization hours of thermal power; $Q$ is the calorific value of standard coal $(\mathrm{kcal} / \mathrm{kg}) ; q$ is the calorific value of coal $(\mathrm{kcal} / \mathrm{kg}) ; b$ is the standard coal consumption for power supply $(\mathrm{g} / \mathrm{kWh}) ; p_{c}$ is the coal price; $\mathrm{AOE}_{2}$ is the annual operating expenses of thermal power.

Annual operating expenses (AOE) for the units is given by the following equation:

$$
\mathrm{AOE}=\mathrm{LLC}+\frac{O \& M+\mathrm{LRC}}{\mathrm{AEP}}
$$

where LLC is the land lease cost (\$/year); O\&M is the annual operation and maintenance cost of wind power (\$/year); LRC is the levelized replacement/overhaul cost (\$/year); AEP is the annual energy production $(\mathrm{kW} \cdot \mathrm{h} /$ year $)$.

2.2. Transmission Cost of Unit Electricity. The transmission cost of unit electricity refers to the annual transmission cost at given annual electricity received by load per $W$. The annual transmission cost of wind power is calculated as shown in the following equation [27]:

$$
C_{\text {trans }}=\frac{C_{\text {infra }}+C_{\text {loss }}+C_{O \& M}}{W},
$$

where $C_{\text {infra }}$ is the annual total investment in power transmission and transformation (\$/year); $C_{\text {loss }}$ is the electricity loss cost of transmission lines (\$/year); $C_{O \& M}$ is the annual operation and maintenance cost of lines (\$/year); and $W$ is the annual electricity received by load $(\mathrm{kW} \cdot \mathrm{h} /$ year $)$.

2.2.1. Annual Total Investment in Transmission Systems. In this study, $C_{\text {infra }}$ is the annual value calculated from the total fixed investment in the transmission system:

$$
C_{\text {infra }}=I \times \mathrm{CRF}_{3} \text {, }
$$

where $I$ is the total investment in transmission and transformation (\$) and $\mathrm{CRF}_{3}$ is the fixed charge rate of transmission and transformation.

The investment in transmission cost consists of the line, converter/substation, and reactive power compensation. The following equations are applied. As no reactive power needs to be compensated for DC transmission, the investment in DC transmission consists of the line and converter station only. For DC transmission, $I_{3}=0$. For AC transmission, reactive power compensation needs to be considered as high reactive power not only occupies the line capacity but also causes substantial active power loss. The investment in AC transmission consists of the line, substation, and reactive power compensation devices:

$$
\begin{aligned}
I & =I_{1}+I_{2}+I_{3}, \\
I_{1} & =2 P_{\max } \times I_{\text {unit } 1}, \\
I_{2} & =L_{e}+I_{\text {unit } 2} \\
I_{3} & =C_{\text {com }} \times P_{\text {com }},
\end{aligned}
$$

where $I_{1}$ is the total investment of converter/substation (\$); $I_{2}$ is the total investment of transmission lines (\$); $I_{3}$ is the total investment of reactive power compensation devices (\$); $P_{\max }$ is the maximum power of DC/AC line (MW); $I_{\text {unit } 1}$ is the converter/substation investment of unit capacity (\$/MVA); $L_{e}$ is the transmission distance $(\mathrm{km}) ; I_{\text {unit2 }}$ is the $\mathrm{DC} / \mathrm{AC}$ line investment per unit length $(\$ / \mathrm{km}) ; C_{\mathrm{com}}$ is the compensator investment of unit capacity ( $\$ /$ Mvar); and $P_{\text {com }}$ is the compensator capacity (Mvar).

2.2.2. Electricity Loss Cost of Transmission Lines. Annual electricity loss cost $C_{\text {loss }}$ refers to the loss cost calculated by multiplying the annual electricity loss and generation cost [14]. The electricity loss in transmission can be further divided into line loss and converter/substation loss, as shown in equations (8)-(13).

$$
\begin{aligned}
& C_{\text {loss }}=C_{\text {wind }} \times W_{\text {loss }}, \\
& W_{\text {loss }}=W_{\text {loss_t } t}+W_{\text {loss } \_l},
\end{aligned}
$$




$$
\begin{aligned}
& W_{\text {loss_t }}=2 r_{\text {loss } \_t} \times P_{\max } \times \tau, \\
& W_{\text {loss } \_l}=P_{\max } \times r_{\text {loss } \_l} \times \tau,
\end{aligned}
$$

where $W_{\text {loss }}$ is the annual electricity loss (MW.h/year); $W_{\text {loss_t }}$ is the annual electricity loss of converter/substation stations (MWh/year); $W_{\text {loss_l }}$ is the annual electricity loss of lines $\left(\mathrm{MWh} /\right.$ year); $r_{\text {loss } t} t$ is the power loss rate of converter/ substation stations; $P_{\max }$ is the maximum power of $\mathrm{DC} / \mathrm{AC}$ lines (MW); $\tau$ is the maximum load loss hours $(\mathrm{h}) ; r_{\text {loss } \_l}$ is the power loss rate of DC/AC lines.

The power loss rate of DC line:

$$
r_{\text {loss } \_l}=\frac{P_{\max } \times R \times L_{e}}{2 U_{n}^{2}},
$$

where $R$ is the resistance per unit length $(\Omega / \mathrm{km})$ and $U_{n}$ is the rated voltage of lines $(\mathrm{kV})$.

The power loss rate of AC line:

$$
r_{\text {loss } \_l}=\frac{P_{\max } \times R \times L_{e}}{U_{n}^{2}} .
$$

2.2.3. Annual Operation and Maintenance Cost. The annual operation and maintenance expense rate $r_{\text {oper }}$ is calculated according to [28]; then the annual operation and maintenance cost $C_{O \& M}$ is given by the following equation:

$$
C_{O \& M}=I \times r_{\text {oper }} \text {. }
$$

2.3. Integration Cost Model of Unit Electricity. Wind power integration cost $C_{\text {int }}$ refers to the expenses incurred by a grid for consuming unit electricity in a safe and stable manner. It consists of the ancillary cost $C_{\text {service }}$ and the profile cost $C_{\text {profile }}[9]$, as shown in the following equation:

$$
C_{\text {int }}=C_{\text {service }}+C_{\text {profile }} \text {. }
$$

2.3.1. Ancillary Cost. The ancillary cost of unit electricity consists of balance cost $C_{\text {balance }}$ incurred for stabilizing grid fluctuations and adjusting units' ramping as well as backup cost $C_{\text {backup }}$ due to the lower capacity reliability of wind power:

$$
C_{\text {service }}=C_{\text {balance }}+C_{\text {backup }} \text {. }
$$

(1) Balance Cost. The balance cost refers to the cost incurred in applying a series of measures to maintain the steady state of the power system and balance the active and reactive power in response to output variability of intermittent renewable energy. Previous studies find that the balance cost of wind power increases with the penetration level due to several factors: the addition of supply to a small control area, forecast errors, interhour variability, intrahour energy balance, and regulation [9]. Reference [3] shows the trend of balance cost in relation to the penetration. In this paper, the balance cost is generalized and fitted by the polynomial fitting method as shown in equation (17) [14]. There may be a little inaccuracy in this method, but it can correctly reflect the general trend:

$$
\begin{aligned}
C_{\text {balance }}= & 1.341 \times 10^{-9} \times k^{3}-4.435 \times k^{2} \\
& +14.63 \times k+0.3105 .
\end{aligned}
$$

(2) Backup Cost. Renewable energy, such as wind power, has lower capacity reliability than those of traditional thermal power units; therefore, the power system needs backup capacity to fill the gap between output and load, particularly under peak load, large variability, and prediction error. The cost incurred by such backup capacity is referred to as backup cost.

In this study, thermal power units are taken as backup capacity. Assume that the capacity of a wind farm is $P_{\text {wind }}$, and its capacity confidence is $\alpha_{\text {wind }}$, while the capacity credit of power system is $\alpha$. Then, the capacity of $P_{\text {wind }}\left(\alpha-\alpha_{\text {wind }}\right)$ needs to be spared by thermal power units. The resulting backup cost is calculated as shown in equation (18). $P_{\text {wind }}$ in the numerator and denominator are eliminated:

$$
C_{\text {backup }}=\frac{\left(\alpha-\alpha_{\text {wind }}\right) \times C_{\text {unit } 2} \times \mathrm{CRF}_{2}}{T_{\text {wind }}},
$$

where $\alpha$ is the capacity credit of power system and $\alpha_{\text {wind }}$ is the capacity credit of wind power.

Previous studies find that the capacity reliability of wind turbines decreases with the penetration level [29]. Reference [30] shows the trend of capacity reliability in relation to the penetration. In this paper, the rational number fitting method is used to obtain the relationship between capacity reliability and penetration level. The relationship is shown in the following equation [14]:

$$
\alpha_{\text {wind }}=0.384 \times k^{2}-0.6905 \times k+0.3975 \text {. }
$$

2.3.2. Profile Cost. After the integration of wind power, with reduced full-load hours (FLH) of conventional units, particularly those for base load and intermediate load, the levelized generation cost of thermal power units will rise as they cannot run at an economical state $[9,31]$. This will result in differences in terms of the marginal cost. Define $C_{\mathrm{FLH}}$ as the difference of marginal generation cost for conventional units timing their power production, and $C_{\text {profile }}$ is the $C_{\mathrm{FLH}}$ of unit wind power production, as shown in the following equation [14]:

$$
C_{\text {profile }}^{i+1}=\frac{C_{\mathrm{FLH}}}{W_{\text {wind }}^{i+1}}=\frac{\left(C_{\text {thermal }}^{i+1}-C_{\text {thermal }}^{i}\right) \times W_{\text {thermal }}^{i+1}}{W_{\text {wind }}^{i+1}},
$$

where $W_{\text {wind }}$ is the electricity generated by wind power $(\mathrm{kW} \cdot \mathrm{h})$ and $W_{\text {thermal }}$ is the electricity generated by thermal power $(\mathrm{kW} \cdot \mathrm{h})$.

\section{Three Wind Power Development Scenarios and Their Economic Differences}

3.1. Centralized Onshore Wind Power. Large centralized onshore wind power with long-distance transmission is 
typical in China and is the most developed for wind power technology. However, centralized onshore wind power centers are in reverse distribution in relation to load centers, and the long-distance transmission involves high cost and substantial electricity loss. In this study, we assume that HVDC technology is used for transporting wind power from centralized onshore locations as it has the advantages of low construction cost, small loss, large capacity, long life, and unlimited distance of transmission. However, converters for DC transmission are more costly and the current conversion process involves more losses.

From the perspective of investment cost, most centralized onshore wind farms are built in open areas with flat terrain as well as better wind energy resources and weather conditions. Therefore, these locations have lower costs of installation, operation, and maintenance. The design of wind turbines for these locations is also relatively well established, and additional features for low wind speed and offshore turbines are not required, so the cost of the turbines is relatively low.

3.2. Low Wind Speed Power. The areas with low wind speed generally relate to those with an average annual wind speed of $5.3 \mathrm{~m} / \mathrm{s}-6.5 \mathrm{~m} / \mathrm{s}$ and annual utilization hours of wind resources below 2000 hours. Low wind speed power has the following advantages: (1) good distribution grid networks mean that wind power can be absorbed locally to improve utilization efficiency; (2) these areas are also load centers, and therefore grid loss is small as long-distance transmission is not required; and (3) additional line does not need to be erected and the transmission cost is low. In this work, we assume that overhead AC short-distance transmission is used for these locations; therefore, reactive power compensators are required. AC substations have a lower cost and electricity loss rate than DC converters.

However, the terrain in low wind speed areas is generally more complex with high wind shear exponents, particularly in hills and mountains. Special design features are needed for low wind speed to compensate for lower wind energy. The features mostly adopted at present are longer blades and higher towers that will increase the construction cost of turbines.

3.3. Offshore Wind Power. Offshore wind power has a very high generation cost in terms of both initial projects and later maintenance in their life cycle. Compared with ordinary onshore wind power, the additional costs to be considered in the offshore fields are as follows [32]: (1) expenses needed to endure extreme marine environment; (2) higher base cost of offshore wind turbines; (3) transportation and installation cost of offshore units; (4) shipping as well as loading and unloading of equipment; (5) offshore engineering planning and wind measurement are more complex and time-consuming; (6) protection against wave erosion; and (7) the replacement cost of offshore unit components and the operation and maintenance costs of the wind farms are higher.
Although offshore wind power does not have any advantages in terms of cost currently, it has a high annual average wind speed, small wind shear exponent, stable wind force, high utilization hours, and potential for large-scale development. The measures for reducing the OLCOE of offshore wind power include selecting deepwater locations instead of shallow ones, shifting from fixed to floating types, and increasing the capacity of each individual unit.

China's offshore wind power locations are mostly concentrated in the southeast coastal areas. Although they are close to load centers, the transmission cost is still high due to the expensive submarine cables. In this study, we assume that $\mathrm{AC}$ cables are used for transporting power from these locations. Compared with that of onshore substations, the cost of offshore substations is also high due to greater difficulty in their construction, operation, and maintenance.

\section{Case Study}

4.1. Model Parameters. Tables 2 and 3 present the model parameters used in each development scenario based on their characteristics as discussed in Section 3. Centralized onshore, low wind speed, and offshore turbine, respectively, refer to the actual parameters of GW136-4.2 MW, GW1402.5 MW, and GW171-6.45 MW.

4.2. Changes of OLCOE for Wind Power and Its Cost Components under Different Penetration Levels. Figure 1 depicts the changes of OLCOE for wind power in relation to penetration levels for different generation modes. It shows that the OLCOE curve for each scenario generally follows an upward trend. Low wind speed has the lowest OLCOE, the curve of which rises quickly with a growth rate of 0.71 $\$ /(\mathrm{MWh} * 1 \%)$. The OLCOE for onshore and offshore wind power increases almost linearly with penetration levels. The OLCOE for offshore wind power is much higher than that of the other two wind power scenarios, and it is $0.249 \$ / \mathrm{kWh}$ at a penetration level of $5 \%$.

Figure 2 shows the comparison of cost components of three scenarios at penetration levels of 5\%, 25\%, and $45 \%$. In general, the generation cost and transmission cost are overwhelming, and the integration cost has an uptrend with the increase of penetration level. The cost compositions in different scenarios differ from each other greatly. Specifically, the results show the following:

(1) At different penetration levels, the relative size of the costs for different generation modes as well as cost components does not change materially. The balance cost, backup cost, and profile cost, as three components of the integration cost, increase slightly in relation to penetration levels.

(2) For centralized onshore wind power, the highest transmission cost among the three generation modes can be attributed to their long distance to load centers. The cost is nearly twice that of its generation cost. This also explains its high OLCOE even with the lowest generation cost. 
TABLE 2: Wind turbine parameters.

\begin{tabular}{lccc}
\hline Wind turbine parameter & Centralized onshore turbine & Low wind speed turbine & Offshore turbine \\
\hline Rated power $(\mathrm{kW})$ & 4200 & 2500 & 6700 \\
Rotor diameter $(\mathrm{m})$ & 136 & 139.5 & 154 \\
Hub height $(\mathrm{m})$ & 110 & 140 & 103 \\
Rated wind speed $(\mathrm{m} / \mathrm{s})$ & 11.2 & 8.5 & 12.2 \\
Cut-in wind speed $(\mathrm{m} / \mathrm{s})$ & 2.5 & 2.5 & 3 \\
Cut-out wind speed $(\mathrm{m} / \mathrm{s})$ & 25 & 20 & 25 \\
\hline
\end{tabular}

TABLE 3: Transmission cost parameters of onshore, low wind speed, and offshore wind power.

\begin{tabular}{|c|c|c|c|}
\hline Parameter & Onshore $[33,34]$ & Low wind speed [35] & Offshore $[19,36,37]$ \\
\hline Line maximum capacity $P_{\max }(\mathrm{MW})$ & 7200 & 300 & 800 \\
\hline Converter/substation investment of unit capacity $I_{\text {unit1 }}(\$ / M V A)$ & 108180 & 44234 & 60847 \\
\hline Transmission line length $L_{e}(\mathrm{~km})$ & 2191.5 & 50 & 50 \\
\hline Transmission line investment of unit length $I_{\text {unit2 }}(\$ / \mathrm{km})$ & 706990 & 163370 & 1567400 \\
\hline Power loss rate of converter/substation $r_{\text {loss_t }}$ & 0.0075 & 0.004 & 0.004 \\
\hline Maximum load loss hours of line $\tau(\mathrm{h})$ & 3000 & 3000 & 3000 \\
\hline Line resistance of unit length $R(\Omega / \mathrm{km})$ & 0.0063 & 0.0205 & 0.0205 \\
\hline Rated voltage of line $U_{n}(\mathrm{kV})$ & 800 & 220 & 220 \\
\hline Annual operation and maintenance expense rate $r_{\text {oper }}$ & 0.018 & 0.018 & 0.012 \\
\hline Utilization hours of line $T_{\max _{l} l}(\mathrm{~h})$ & 5000 & 5000 & 5000 \\
\hline Compensator cost of unit capacity $C_{\text {com }}(\$ /$ Mvar $)$ & - & 74620 & 74620 \\
\hline Compensator capacity $P_{\text {com }}$ (Mvar) & - & 140 & 140 \\
\hline
\end{tabular}

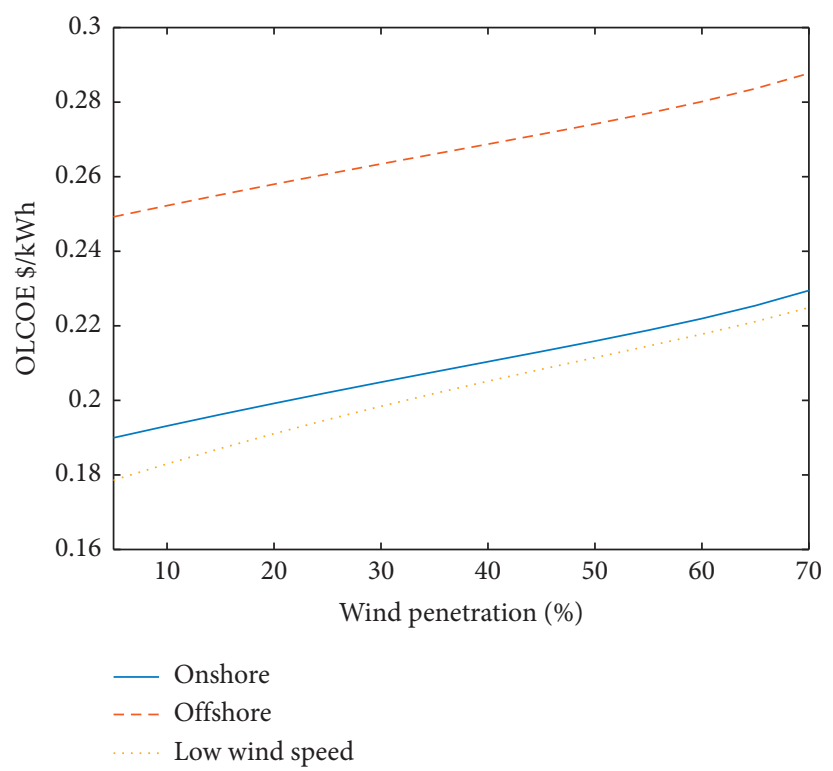

Figure 1: Changes of OLCOE in relation to penetration levels under three development scenarios.

(3) As the power generated can be absorbed locally, low wind speed power has the lowest OLCOE, largely due to the lowest transmission cost with short-distance AC lines used. However, with their small FLH and the design features of a high tower and long blades, they have a high generation cost.

(4) With high FLH offset by the disadvantages of high construction cost and operation and maintenance cost, offshore wind power has a high generation cost. Even with a short transmission distance, high cost of submarine cables and offshore substations renders their transmission cost almost as high as that of centralized onshore wind power.
(5) At a penetration level of 5\%, only the low wind speed has a profile cost that is below zero. Therefore, only in the case of low wind speed, thermal power generation cost shows a downward trend near the penetration level. Since the backup cost is determined by the FLH of wind power, it is the highest for low wind speed.

Figure 3 shows the change of cost components in relation to penetration levels under three scenarios as follows:

(1) The generation and transmission costs do not vary with wind power penetration levels. This is because the generation cost for wind turbines is related to 


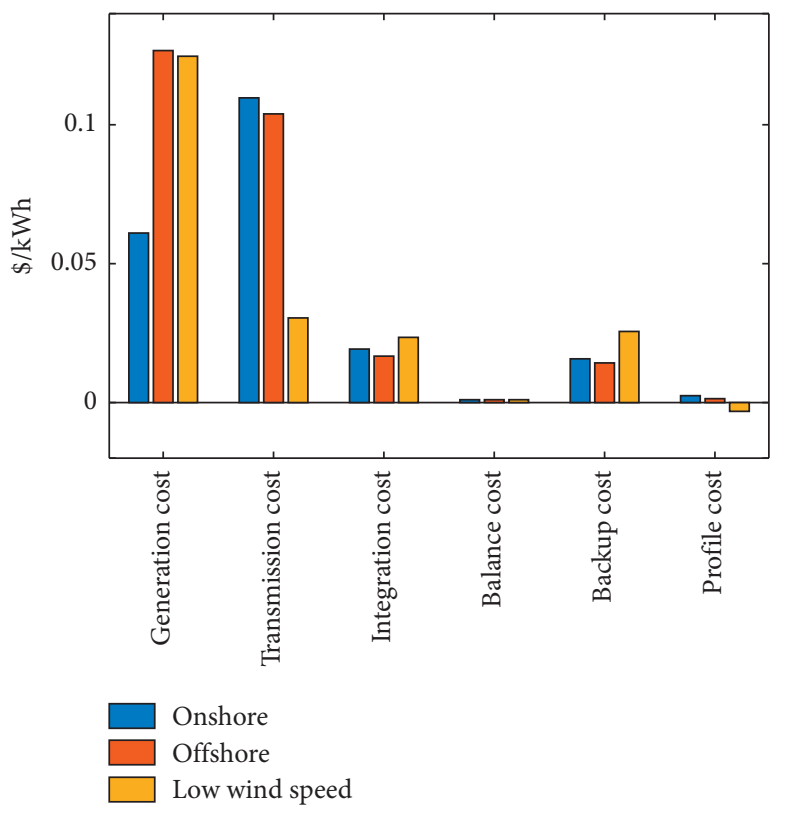

(a)

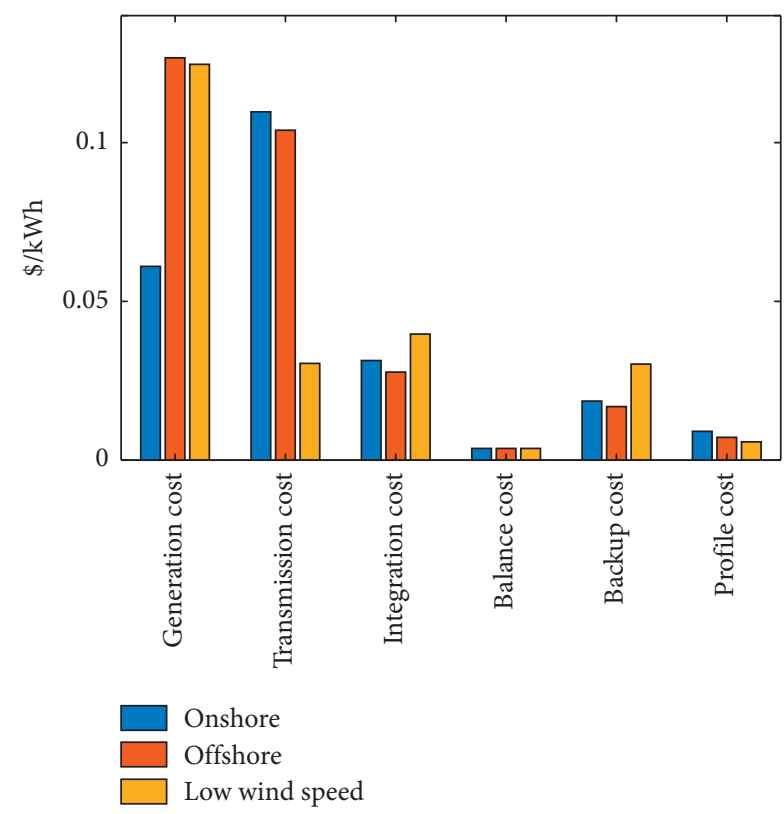

(b)

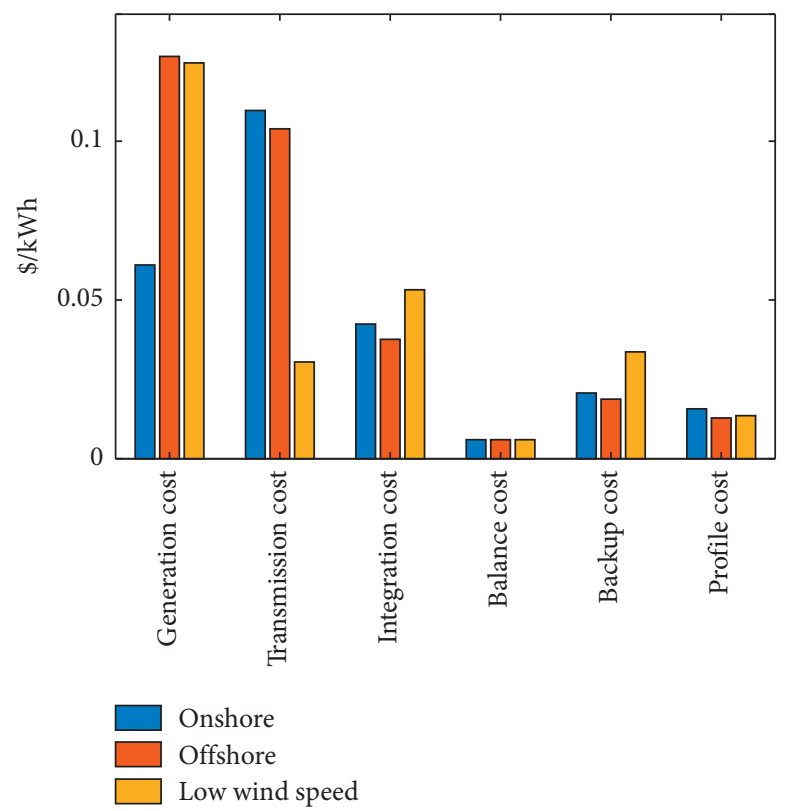

(c)

Figure 2: Comparison of OLCOE cost components for three scenarios under different penetration levels. (a) 5\% penetration level. (b) 25\% penetration level. (c) $45 \%$ penetration level.

their FLH, which in turn is determined by wind resources and control strategies at their locations. The transmission cost is not a function of penetration because both the power transported and its cost allotted according to the penetration levels.

(2) In centralized onshore wind power, the transmission cost is much higher than the generation cost, at 0.110 $\$ / \mathrm{kWh}$ and $0.061 \$ / \mathrm{kWh}$, respectively. The generation cost of the other two generation modes is greater than the transmission cost. For offshore wind power, the generation and transmission costs are 0.127
$\$ / \mathrm{kWh}$ and $0.104 \$ / \mathrm{kWh}$, respectively. Low wind speed provides a similar generation cost to that of offshore wind power.

(3) The integration cost rises sharply with increasing penetration level. For centralized onshore wind power, the integration cost is equal to the generation cost at a penetration level of $70 \%$.

(4) The profile cost rises at the steepest rate among all the components of integration cost, particularly for low wind speed; its growth rate is $0.43 \$ /(\mathrm{MWh} * 1 \%)$ while that for offshore wind power is 0.33 


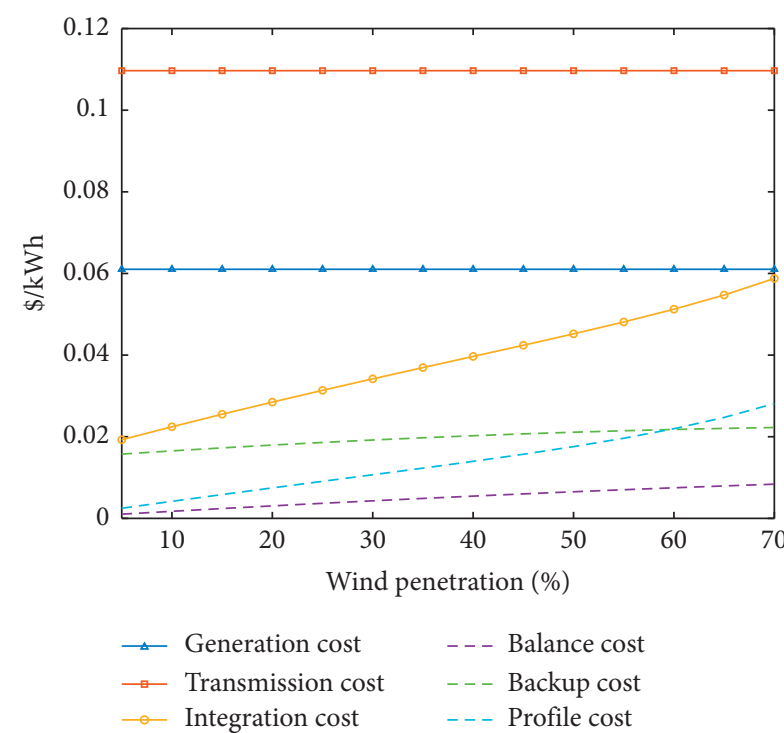

(a)

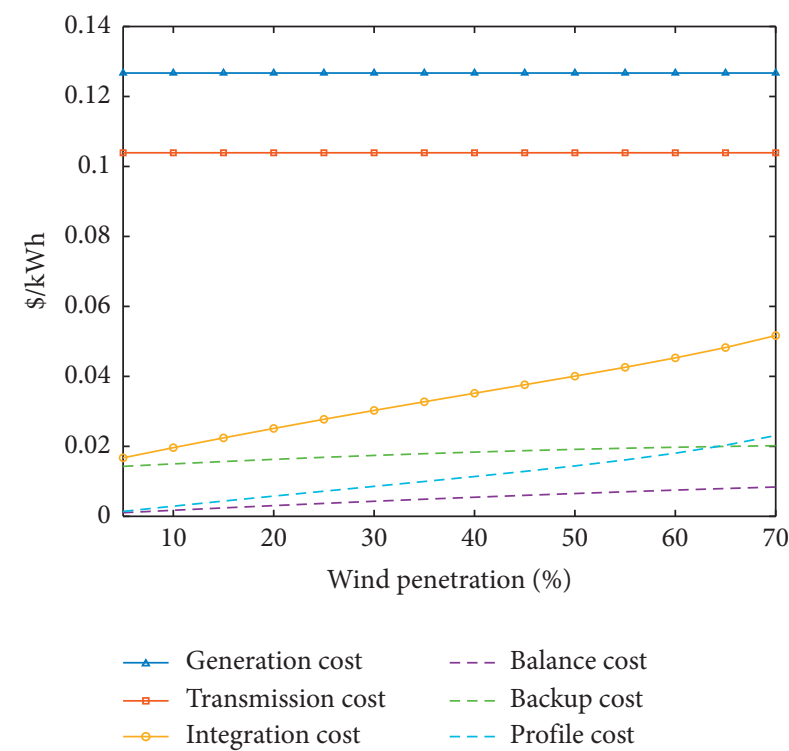

(b)

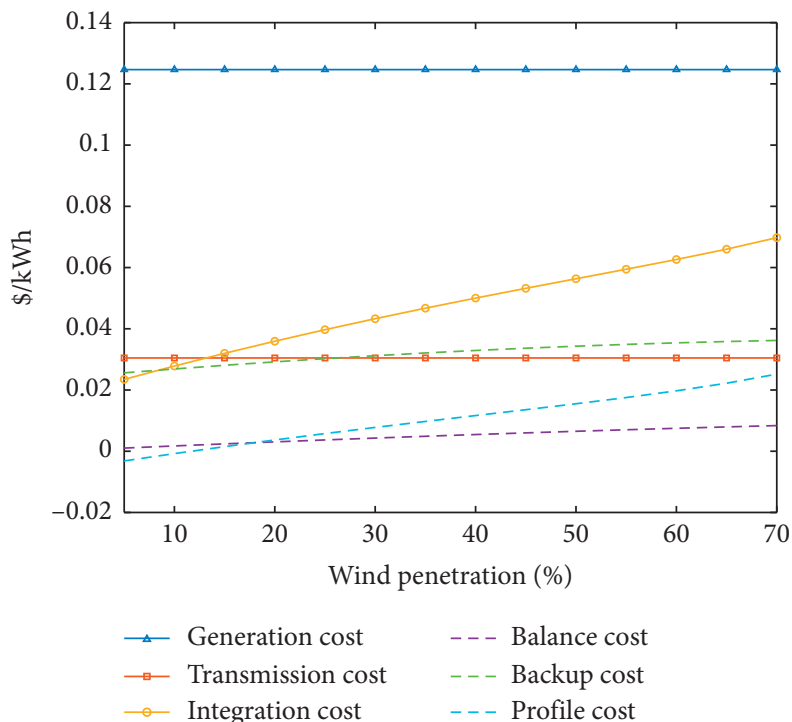

(c)

FIGURE 3: Changes of each cost component in relation to penetration levels under different scenarios. (a) Centralized onshore. (b) Offshore wind power. (c) Low wind speed.

$\$ /(\mathrm{MWh} * 1 \%)$. For low wind speed, the profile cost is negative when the penetration level is less than $10 \%$.

(5) Although the base of backup cost is relatively high, it grows slowly with the increase of penetration levels. Due to low FLH of low wind speed power, more backup units of thermal power are required, and therefore the backup cost is the highest of the three scenarios at $0.036 \$ / \mathrm{kWh}$. The profile cost for centralized onshore and offshore wind power exceeds their backup cost at penetration levels of $55 \%$ and $65 \%$, respectively, while that for low wind speed has never been higher than the backup cost.
4.3. Changes of Integration Cost in relation to Penetration Levels. If the load demand remains unchanged, the integration of wind power will reduce the power generated by thermal plants, which will then result in lower FLH and high generation cost for the thermal plants. In addition, the reliability of wind power capacity decreases with the increase of penetration. The unreliable capacity must be compensated by thermal power. Therefore, the additional profile cost and backup cost will rise with increasing the penetration level.

Figure 4 shows the change in the proportion of integration cost in the OLCOE in relation to the penetration levels. The figure shows that the proportion of integration cost is increasing almost linearly. The integration cost of low 


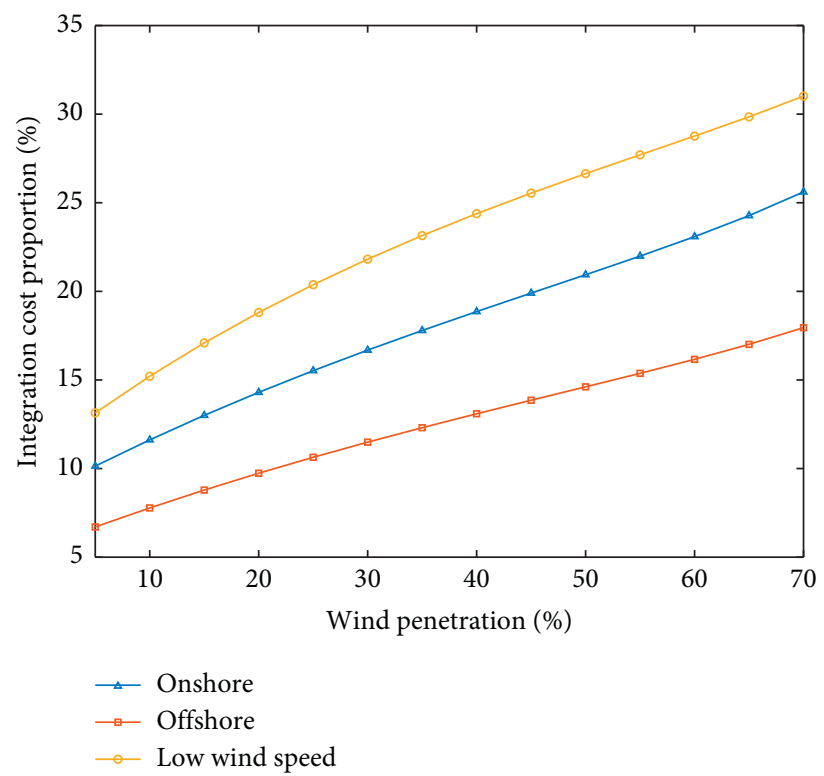

Figure 4: Proportion of integration cost in relation to penetration levels under different scenarios.

wind speed accounts for $14-31 \%$ of the OLCOE, the highest among the three scenarios, while that of offshore wind power is the lowest. As shown in Figure 2, this is mainly due to the fact that low wind speed needs more backup capacity to ensure the reliability of power supply.

\subsection{Changes of Profile Cost and Their Effects on Conventional} Units. Given a constant total load, wind power integration will replace part of the conventional capacity and reduce the power generated by conventional units. However, the relationship between the capacity reliability of wind power and the penetration levels is not linear. Therefore, the FLH of conventional units do not change linearly with penetration. Figure 5 shows the effects of wind power on conventional units under three different scenarios.

As for the influence of wind power on thermal power $\mathrm{FLH}$, the following findings are made:

(1) With the increase in penetration, the FLH of conventional power is gradually reduced under the scenarios of offshore and centralized onshore wind power.

(2) With a high proportion of wind power, the FLH of thermal power will drop even faster. This is because wind power has lower capacity confidence at a high penetration, and more backup thermal power units are needed to absorb each kilowatt-hour of wind power. This part of reserve capacity is usually operated in a noneconomic state. In the offshore case, the decline rate of thermal FLH increases from 15 to $59 \mathrm{~h}$ per $1 \%$ penetration.

(3) As the FLH of offshore wind power are higher than those of the other two, they have the greatest effect on conventional units in the system. Therefore, the thermal FLH will drop at the highest speed. Offshore wind power has an average decreasing rate of $46.6 \mathrm{~h}$ per $1 \%$ penetration, while that for centralized onshore wind power is $46.2 \mathrm{~h}$ per $1 \%$ penetration.

(4) In the case of low wind speed, thermal FLH shows a slightly increasing trend when the penetration level is low (below 10\%), indicating that low wind speed power at low penetration levels is beneficial to reducing thermal generation cost. This may be due to the fact that, at low penetration in low wind speed scenarios, the capacity confidence of wind power is relatively high, while FLH of low wind speed are relatively low. The task of thermal power units is more to bear the base load, rather than as a backup. Therefore, when the proportion of wind power increases, the capacity of thermal power units as reserves will be reduced more, so the FLH of thermal power will increase slightly. However, at a relatively high penetration, the base load is transferred from thermal power plants to wind power plants. Thermal power units are more used as backups, resulting in a decrease of FLH.

As for the profile costs under different wind power ratios and different development scenarios, the following findings are made:

(1) It can be seen from equation (20) that the profile cost of wind power is positively correlated to the growth rate of the thermal generation cost. Due to the dropping FLH with an increasingly faster speed, the generation cost of thermal power gets higher and grows faster at high penetration. Therefore, the profile cost increases with the penetration level.

(2) Similar to the FLH, the greater the effect on conventional units, the greater the profile cost of wind power. Therefore, the profile cost for offshore wind power is the highest among the three scenarios. 


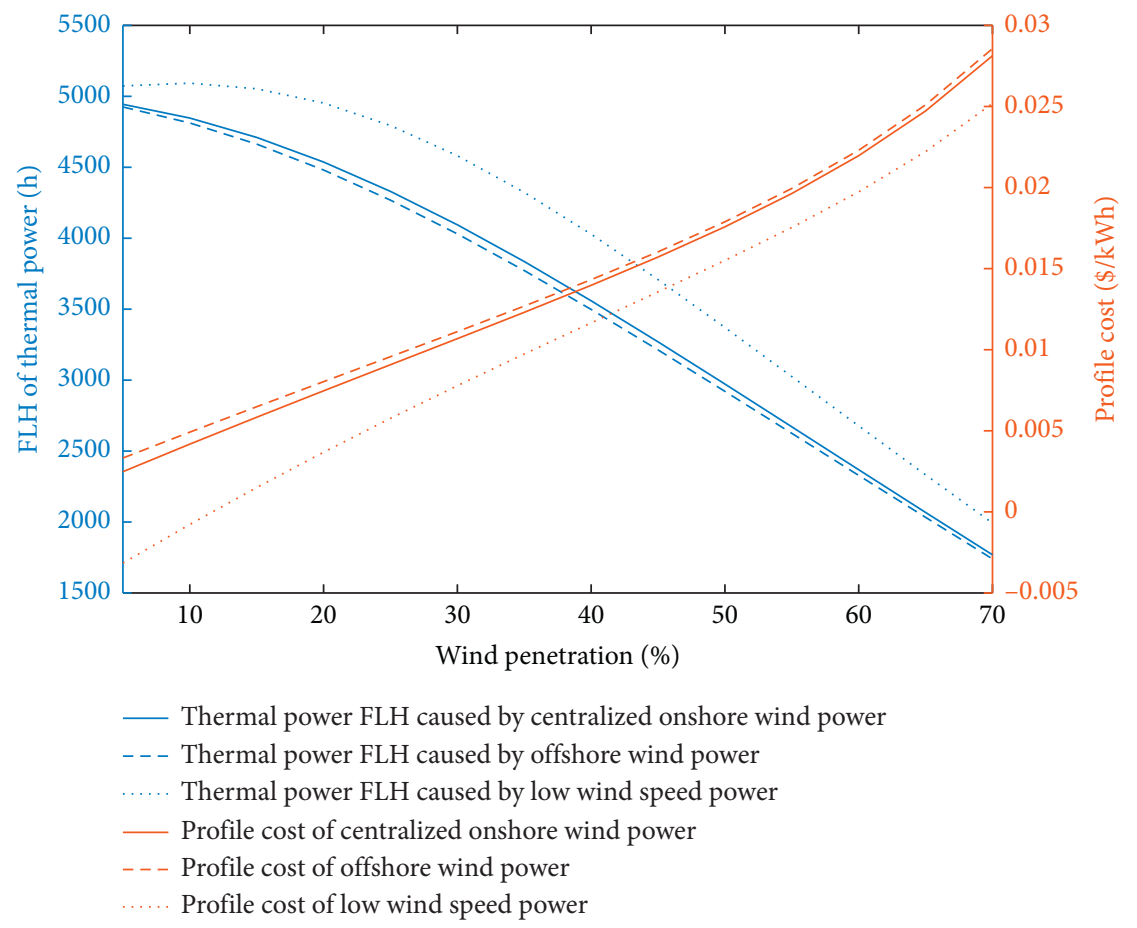

FIgURE 5: Changes in thermal FLH and profile cost with increasing penetration levels for various scenarios.

(3) Although the profile cost for low wind speed is negative at low penetration levels, it has a high growth rate.

4.5. Sensitivity Analysis. According to the above analysis, OLCOE of wind power is jointly determined by many variables. A sensitivity analysis is conducted to clearly identify how dependent the OLCOE is on various variables. The parameters that have a great impact on the generation cost, transmission cost, and integration cost, that is, the FLH of wind power, transmission distance, and capacity confidence of wind power, are selected for sensitivity analysis under the scenario of $30 \%$ wind power ratio.

Figures 6-8 show the variation trend of wind power OLCOE and its cost components with increasing FLH, transmission distance, and capacity confidence. In general, under the $30 \%$ ratio of wind power, the FLH and transmission distance has a greater impact on OLCOE.

It can be seen from Figure 6 that various costs are reduced to varying degrees with the growth of wind power FLH. In addition, the reduction in generation costs is the most obvious. This is because the generation cost is closely related to the annual power generation and FLH of wind power. The higher the FLH, the lower the investment as well as the operation and maintenance costs allocated to each $\mathrm{kWh}$ of wind power. However, as FLH of wind power becomes higher and higher, the downward trend of OLCOE will become more and more gentle. In the stage when the FLH increases from $1500 \mathrm{~h}$ to $2000 \mathrm{~h}$, OLCOE decreased by $0.027 \$$, while in the $3000 \mathrm{~h}-3500 \mathrm{~h}$ period, OLCOE only decreased by $0.008 \$$. This is because with the gradual increase of FLH, although the levelized cost of

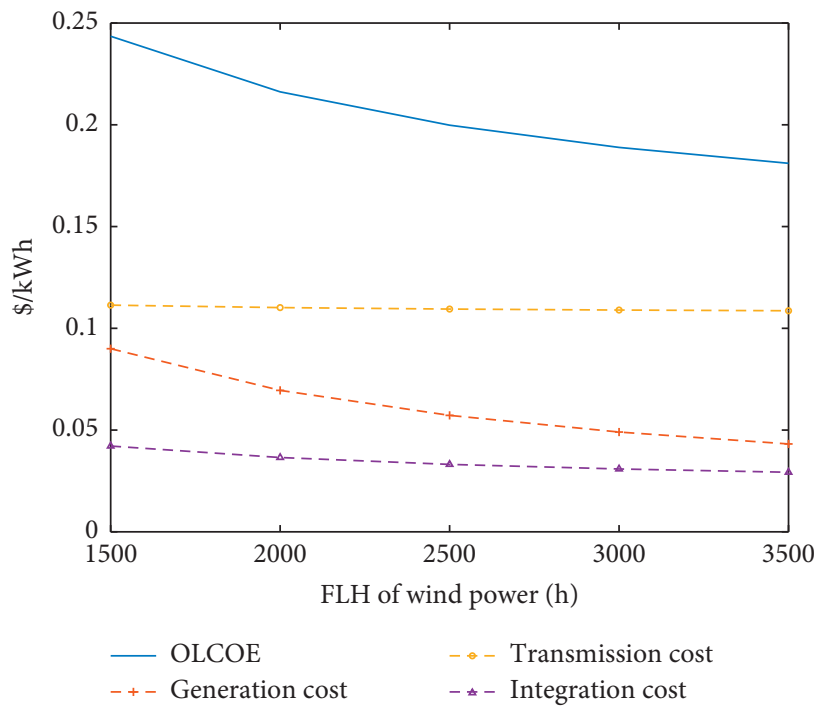

Figure 6: Changes of OLCOE and each cost component with increasing FLH of wind power.

wind turbines is reduced, the variable operating costs (i.e., the operating and maintenance costs required for generating each kilowatt-hour of wind power) remain unchanged.

It can be seen from Figure 7 that the transmission distance only affects the transmission cost. OLCOE is linearly related to the transmission distance. For every $500 \mathrm{~km}$ increase in transmission distance, OLCOE increases by $0.013 \$$.

It can be seen from Figure 8 that the confidence level of wind power capacity only affects the integration cost. The 


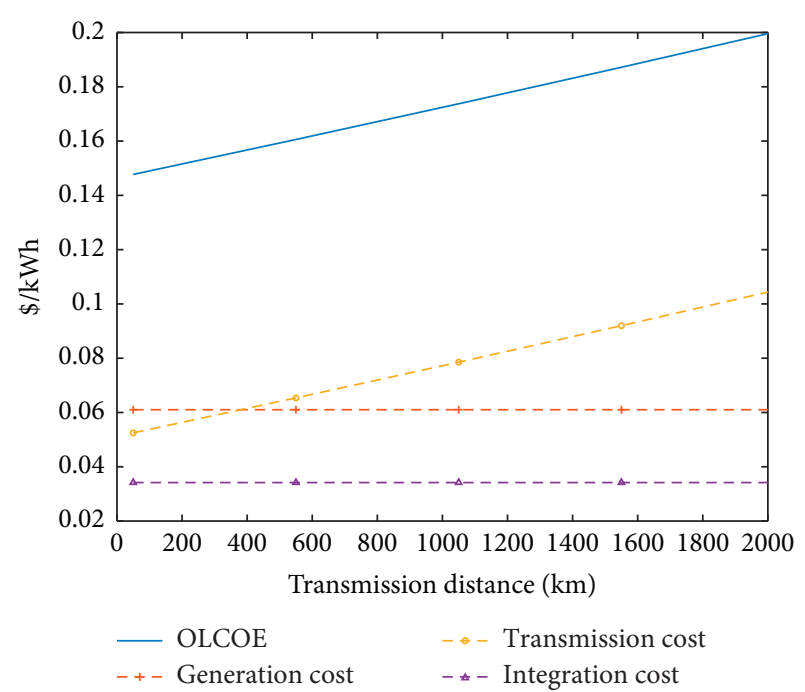

Figure 7: Changes in OLCOE and each cost component with increasing transmission distance.

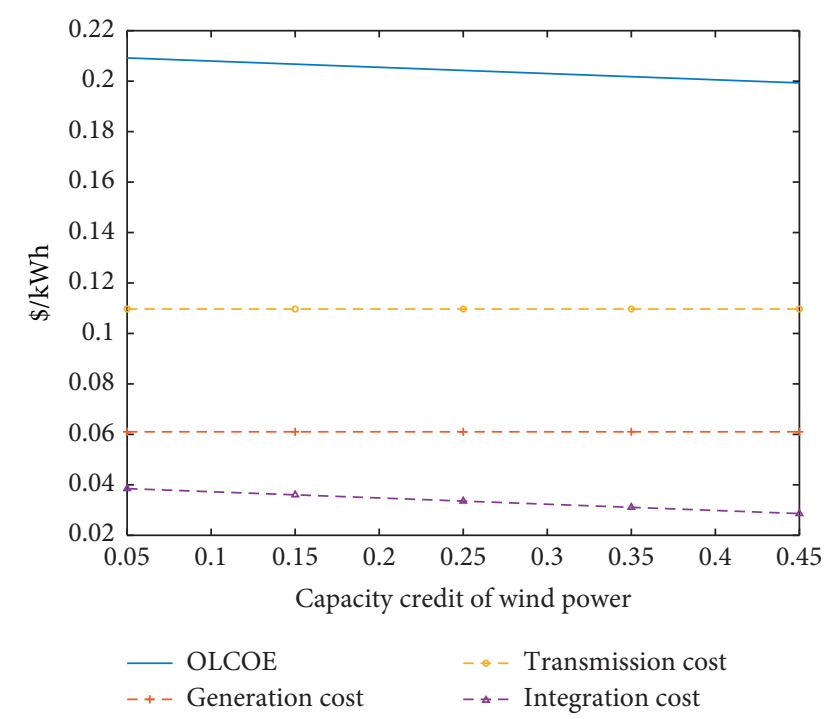

FIgURE 8: Changes of OLCOE and each cost component with increasing capacity credit of wind power.

capacity confidence of wind power indicates the capacity of conventional units that wind turbines can replace. In scenarios with high confidence in wind power capacity, fewer backup conventional units are required; thus, the integration costs will be lower. With the increase in capacity confidence, OLCOE declines but not significantly (the rate of decrease is $0.025 \$$ /unit capacity confidence).

\section{Conclusions}

In this work, for three development scenarios of wind power in China-large wind power bases that require long-distance transmission, offshore wind power that is under large-scale development, and those with low wind speed-we propose methods for calculating the OLCOE for the different scenarios. Given the differences between various sources of wind power, we analyse the OLCOE and its components for various development modes and present the distribution of various costs at different penetrations.

The results indicate that, in the current scenario, low wind speed power has the best economy due to its advantage of being close to the load center. The development of low wind speed power at low penetration is conducive to economically reform the conventional units in the transformation of the power system. The largescale development of offshore wind power requires a reduction in the cost of offshore wind turbines and submarine cables. At present, onshore centralized wind power has economic advantages. But its technology is relatively mature; hence, there is little room for its cost reduction.

The details of the findings are as follows:

(1) The OLCOE curve of wind power for each scenario generally follows an upward trend. The OLCOE for low wind speed is the lowest, while that for offshore wind power is the highest with a large gap between the other two cases.

(2) For centralized onshore wind power, the generation cost is the lowest $(0.061 \$ / \mathrm{kWh})$ and the transmission cost is the highest $(0.110 \$ / \mathrm{kWh})$.

(3) Offshore wind power has the highest generation cost of $0.127 \$ / \mathrm{kWh}$. Its transmission cost of $0.104 \$ / \mathrm{kWh}$ almost catches up with that of centralized onshore wind power.

(4) Low wind speed power has the lowest transmission cost $(0.030 \$ / \mathrm{kWh})$ and a high generation cost $(0.125$ $\$ / \mathrm{kWh})$.

(5) With the increase of penetration level, the integration cost continues to increase. The integration cost for low wind speed accounts for $14-31 \%$ of the OLCOE, the highest proportion among the three wind power scenarios.

(6) Offshore wind power has the highest profile cost. Although the profile cost for low wind speed is negative at low penetration levels, it has a high growth rate.

(7) FLH of wind power and transmission distance influence the OLCOE to a large extent.

\section{Data Availability}

The data used to support the findings of this study are included within the article.

\section{Conflicts of Interest}

The authors declare no conflicts of interest.

\section{Acknowledgments}

This research was funded by the project of State Grid Jiangxi Electric Power Research Institute (52182018001F). 


\section{References}

[1] Z. M. Wang and Z. N. Lu, "Techno-economic analysis on cost structure and operation value of the wind power project," Science Management Research, vol. 27, no. 2, pp. 51-54, 2009, in Chinese.

[2] H. Q. Yu, China's Wind Power Development Study of the Cost and Wind Power Generators Selection, North China Electric Power University, Beijing, China, 2009, in Chinese.

[3] E. D. Delarue, P. J. Luickx, and W. D. D'haeseleer, "The actual effect of wind power on overall electricity generation costs and CO2 emissions," Energy Conversion and Management, vol. 50, no. 6, pp. 1450-1456, 2009.

[4] Q. Tu, R. Betz, J. Mo, Y. Fan, and Y. Liu, "Achieving grid parity of wind power in China - present levelized cost of electricity and future evolution," Applied Energy, vol. 250, pp. 10531064, 2019.

[5] J. Aldersey-Williams, I. D. Broadbent, and P. A. Strachan, "Better estimates of LCOE from audited accounts-a new methodology with examples from United Kingdom offshore wind and CCGT," Energy Policy, vol. 128, pp. 25-35, 2019.

[6] M. I. Blanco, "The economics of wind energy," Renewable and Sustainable Energy Reviews, vol. 13, no. 6-7, pp. 1372-1382, 2009.

[7] C.-T. Li, H. Peng, and J. Sun, "Life cycle cost analysis of wind power considering stochastic uncertainties," Energy, vol. 75, pp. 411-418, 2014.

[8] B. Lin and W. Wu, "Cost of long distance electricity transmission in China," Energy Policy, vol. 109, pp. 132-140, 2017.

[9] J. F. DeCarolis and D. W. Keith, "The costs of wind's variability: is there a threshold?" The Electricity Journal, vol. 18, no. 1, pp. 69-77, 2005.

[10] L. Hirth, F. Ueckerdt, and O. Edenhofer, "Integration costs and the value of wind power," SSRN Electronic Journal, 2012.

[11] F. Ueckerdt, L. Hirth, G. Luderer, and O. Edenhofer, "System LCOE: what are the costs of variable renewables?" Energy, vol. 63, pp. 61-75, 2013.

[12] J. Yan, Y. Liu, S. Han, Y. Wang, and S. Feng, "Reviews on uncertainty analysis of wind power forecasting," Renewable and Sustainable Energy Reviews, vol. 52, pp. 1322-1330, 2015.

[13] J. Yan, F. Li, Y. Liu et al., "Novel cost model for balancing wind power forecasting uncertainty," IEEE Transactions on Energy Conversion, vol. 32, no. 1, pp. 318-329, 2016.

[14] Y. Liu, C. Liang, J. Yan et al., "Overall levelized cost of energy for a large-scale wind farm base with long-distance transmission and accommodation," Proceedings of the CSEE, vol. 40, no. 2, pp. 500-509, 2020.

[15] M. Varvara and A. J. Kolios, "Techno-economic optimization of offshore wind farms based on life cycle cost analysis on the UK," Renewable Energy, vol. 132, pp. 439-454, 2019.

[16] V. Mytilinou, A. J. Kolios, and G. D. Lorenzo, “A comparative multi-disciplinary policy review in wind energy developments in Europe," International Journal of Sustainable Energy, vol. 36, no. 8, pp. 1-21, 2015.

[17] S.-Y. Lin and J.-F. Chen, "Distributed optimal power flow for smart grid transmission system with renewable energy sources," Energy, vol. 56, pp. 184-192, 2013.

[18] H. Y. Chen, K. Tan, S. T. Xi et al., "A model for calculating operation period cost of offshore wind power," Automation of Electric Power Systems, vol. 38, no. 13, pp. 135-139, 2014, in Chinese.
[19] Z. C. Zhang, J. T. Guo, H. J. Zhu et al., "Optimization scheme of offshore wind power grid connection based on LCC model," Power System Protection and Control, vol. 45, no. 21, pp. 51-57, 2017, in Chinese.

[20] A. Myhr, C. Bjerkseter, A. Ågotnes, and T. A. Nygaard, "Levelised cost of energy for offshore floating wind turbines in a life cycle perspective," Renewable Energy, vol. 66, pp. 714728,2014

[21] H. Holttinen, P. Meibom, A. Orths et al., "Impacts of large amounts of wind power on design and operation of power systems, results of IEA collaboration," Wind Energy, vol. 14, no. 2, pp. 179-192, 2011.

[22] C. S. Chen, Research on System Cost and Block Value of Wind power, Southeast University, Nanjing, China, 2015, in Chinese.

[23] L. Li, Y. X. Zhang, C. S. Chen et al., "Calculation of wind power variation costs and its application research," Proceedings of the CSEE, vol. 36, no. 19, pp. 5396-5396, 2016, in Chinese.

[24] J. Y. Chai and S. Y. Zhang, "Total cost and energy cost of wind turbine generation systems for low wind speeds," Journal of Tsinghua University Science and Technology, vol. 51, no. 3, pp. 356-360, 2011, in Chinese.

[25] L. Fingersh, M. Hand, and A. Laxson, Wind Turbine Design Cost and Scaling Model, National Renewable Energy Lab (NREL), Golden, CO, USA, 2006.

[26] R. B. Shen, L. Z. Zhang, H. Zhang et al., "Comparative research on the economy of coal transportation and power transmission," Electric Power, vol. 46, no. 10, pp. 133-139, 2013, in Chinese.

[27] H. Zhao, S. Guo, and H. Li, "Economic impact assessment of wind power integration: a quasi-public goods property perspective," Energies, vol. 8, no. 8, pp. 8749-8774, 2015.

[28] R. Karki and R. Billinton, "Cost-effective wind energy utilization for reliable power supply," IEEE Transactions on Energy Conversion, vol. 19, no. 2, pp. 435-440, 2004.

[29] H. Weigt, "Germany's wind energy: the potential for fossil capacity replacement and cost saving," Applied Energy, vol. 86, no. 10, pp. 1857-1863, 2009.

[30] P. Heptonstall, R. Gross, and F. Steiner, The Costs and Impacts of Intermittency-2016 Update: A Systematic Review of the Evidence on the Costs and Impacts of Intermittent Electricity Generation technologies, UK Energy Research Centre (UKERC), London, UK, 2017.

[31] Z. Liu, W. Zhang, C. Zhao, and J. Yuan, "The economics of wind power in China and policy implications," Energies, vol. 8, no. 2, pp. 1529-1546, 2015.

[32] J. Xu, Y. Jin, C. C. Hu et al., "Research on combined power transmission scheme for offshore windfarm cluster," $A d$ vances of Power System \& Hydroelectric Engineering, vol. 32, no. 11, pp. 107-113, 2016, in Chinese.

[33] Y. Zhao, B. Han, and G. L. Fang, "A survey of condition monitoring and fault diagnosis for wind power generators," Thermal Power Generation, vol. 45, no. 10, pp. 1-5, 2016, in Chinese.

[34] B. Li and X. J. Du, "The comprehensive cost analysis of HVDC transmission project based on different voltage levels," Construction \& Design for Project, no. 1, pp. 128-130, 2017, in Chinese.

[35] H. Yao, X. N. Huang, G. Yu et al., Cost of Power Engineering Projects Put into Operation during the 11th Five-Year Plan period, State Electricity Regulatory Commission, Beijing, China, 2012, in Chinese. 
[36] B. J. Cheng, Z. Xu, Y. W. Xuan et al., "Economic comparison of AC/DC power transmission system for submarine cables," Electric Power Construction, vol. 35, no. 12, pp. 131-136, 2014, in Chinese.

[37] M. Zheng and C. H. Wang, "Research on the transmission mode of offshore wind farm," Southern Energy Construction, no. 2, pp. 99-108, 2018, in Chinese. 